\title{
Expiratory Flow Limitation as a Risk Factor for Pulmonary Complications After Major Abdominal Surgery
}

\author{
Savino Spadaro, MD,* Gaetano Caramori, MD, † Chiara Rizzuto, MD,* Francesco Mojoli, MD, $\neq$ \\ Gianluca Zani, MD, ${ }^{*}$ Riccardo Ragazzi, MD, ${ }^{*}$ Giorgia Valpiani, StatD,§ Francesca Dalla Corte, MD,* \\ Elisabetta Marangoni, MD,* and Carlo Alberto Volta, MD*
}

BACKGROUND: Postoperative pulmonary complications are major causes of postoperative morbidity and mortality. Although several risk factors have been associated with postoperative pulmonary complications, they are not consistent between studies and, even in those studies in which these factors were identified, the predictive power is low. We hypothesized that postoperative pulmonary complications would correlate with the presence of intraoperative expiratory flow limitation.

METHODS: Candidates for this prospective observational study were patients undergoing general anesthesia for major abdominal surgery. Preoperative data collection included age, body mass index, American Society of Anesthesiologists class, smoking and dyspnea history, and room air $\mathrm{PO}_{2}$. Expiratory flow limitation was assessed intraoperatively using the positive endexpiratory pressure test. Postoperative data collection included the incidence of postoperative pulmonary complications.

RESULTS: Of the 330 patients we enrolled, 31\% exhibited expiratory flow limitation. On univariate analysis, patients with expiratory flow limitation were more likely to have postoperative pneumonia (5\% vs $0 \%, P<.001)$ and acute respiratory failure $(11 \%$ vs $1 \%, P<.001)$ and a longer length of hospital stay ( 7 vs 9 days, $P<.01$ ). Multivariate analysis identified that expiratory flow limitation increased the risk of developing postoperative pulmonary complications by $>50 \%$ (risk ratio, 2.7; 95\% confidence interval, 1.7-4.2). Age and Medical Research Council dyspnea score were also significant multivariate risk factors for pulmonary complications.

CONCLUSIONS: Our results show that intraoperative expiratory flow limitation correlates with that of postoperative pulmonary complication after major abdominal surgery. Further work is needed to better understand the relevance of expiratory flow limitation on postoperative pulmonary outcomes. (Anesth Analg 2016;XXX:00-00)

$\mathrm{P}$ ostoperative pulmonary complications (PPCs) are a major cause of postoperative morbidity, mortality, and increased length of hospital stay. ${ }^{1}$ Traditionally, several risk factors have been associated with PPCs, including age, chronic obstructive pulmonary disease (COPD), cigarette use, congestive heath failure, functional dependence, obesity, and obstructive sleep apnea. ${ }^{1-4}$ In a 2010 multicenter trial, Canet et $\mathrm{al}^{5}$ used multivariable logistic regression to

From the *Dipartimento di Morfologia, Chirurgia e Medicina Sperimentale Unità Operativa di Anestesia e Rianimazione, Azienda OspedalieroUniversitaria S. Anna, Università di Ferrara, Ferrara, Italy; †Centro Interdipartimentale per lo Studio delle Malattie Infiammatorie delle Vie Aeree e Patologie Fumo-correlate (CEMICEF; formerly Centro di Ricerca su Asma e BPCO), Sezione di Medicina Interna e Cardiorespiratoria, Università di Ferrara, Ferrara, Italy; ‡Dipartimento di Scienze Clinico-Chirurgiche, Diagnostiche e Pediatriche, Sezione di Anestesia Rianimazione e Terapia Antalgica, Università degli Studi di Pavia, Pavia, Italy; and §Ufficio Ricerca e Innovazione, Azienda Ospedaliero-Universitaria S. Anna, Università di Ferrara, Ferrara, Italy.

Accepted for publication April 27, 2016.

Funding: This study was financially supported by the University of Ferrara, Italy.

The authors declare no conflicts of interest.

Supplemental digital content is available for this article. Direct URL citations appear in the printed text and are provided in the HTML and PDF versions of this article on the journal's website (www.anesthesia-analgesia.org).

Reprints will not be available from the authors.

Address correspondence to Savino Spadaro, MD, Dipartimento di Morfologia, Chirurgia e Medicina Sperimentale, Università di Ferrara, Via Aldo Moro, 844124 Ferrara, Italy. Address e-mail to savinospadaro@gmail.com.

Copyright (C) 2016 International Anesthesia Research Society DOI: 10.1213 /ANE.0000000000001424 identify 7 independent predictors of PPCs including preoperative peripheral capillary oxygen saturation $\left(\mathrm{SpO}_{2}\right)$, respiratory infection in the last month, surgical incision, and duration of surgery. The strongest predictor was a preoperative $\mathrm{Spo}_{2}<90 \%$. Although clinically useful because $\mathrm{Spo}_{2}$ is very easy to determine, patients undergoing major abdominal surgery seldom present with such low $\mathrm{SpO}_{2}$ values. ${ }^{6,7}$ In addition, risk factors for PPCs are not consistent across studies. For example, Smetana et $\mathrm{al}^{2}$ found that smoking history, the American Society of Anesthesiologists physical status classification, and the presence of both COPD and heart failure were predictive of PPCs, whereas the same parameters did not predict PPCs in a subsequent study by Canet et al. ${ }^{5}$ Moreover, even in those studies in which risk factors for PPCs were identified, the odds ratio was relatively low, suggesting a weak predictive ability. Although the reason why risk factors for PPCs are inconsistent between studies is unclear, differences in patient population, underlying disease, drugs used, and new surgical and anesthesiological techniques may all play a role. In addition, the type of surgery might be relevant because predictors appropriate for thoracic surgery such as spirometry or carbon dioxide lung diffusion capacity (DLCO) may not be applicable to patients undergoing major abdominal surgery. For example, spirometry is recommended for the diagnosis of obstructive lung disease but has not translated into effective risk prediction for individual patients. ${ }^{3,8}$ 
We hypothesized that expiratory flow limitation (EFL) would be an important risk factor for PPCs. EFL occurs when at a given lung volume the expiratory flow is independent of the patient's expiratory effort or on an increase of elastic recoil pressure. EFL has been described as occurring immediately after peak expiratory flow is reached during the forced vital capacity maneuver. ${ }^{9}$ However, patients with acute and/or chronic lung disease can experience EFL even during tidal ventilation, suggesting that expiratory flow is markedly reduced and dynamic hyperinflation may be present. ${ }^{10}$ It is not surprising that EFL may help identify patients with greater impairment of lung function and disability. Clinically, EFL is associated with the severity of diseases such as COPD, ${ }^{10}$ acute and chronic heart failure, ${ }^{11,12}$ cystic fibrosis, ${ }^{13}$ acute respiratory distress syndrome, ${ }^{14}$ cardiac surgery, ${ }^{15}$ spinal cord injury, ${ }^{16}$ obesity $^{17}$ sleep apnea, ${ }^{18}$ and bronchiectasis.

In spontaneously breathing patients, the negative expiratory pressure (NEP) test is considered the criterion standard for detecting EFL. ${ }^{9}$ The NEP test, however, is difficult to apply in ventilated patients during anesthesia because it requires a closed circuit and involves other technical difficulties (connection between the NEP system and the expiratory port of the ventilator). Recently, a new bedside method to detect the presence of EFL has been developed. ${ }^{19}$ This method, based on subtracting $3 \mathrm{~cm} \mathrm{H}_{2} \mathrm{O}$ of positive endexpiratory pressure (PEEP test) at the beginning of expiration, has produced results comparable with those obtained with the NEP test. ${ }^{19}$

Patients may develop EFL during general anesthesia because of the reduction of functional residual capacity that occurs with anesthetic induction ${ }^{20}$ and age- and diseasedependent reduction of maximal expiratory flow. ${ }^{21}$ We hypothesized that patients who develop EFL during general anesthesia would have a more compromised maximal expiratory flow than patients without EFL. EFL, which is associated with several different clinical conditions, would then represent an important limitation in lung function and correlate with postoperative respiratory complications. To test our hypothesis, we studied whether EFL during anesthesia was a risk factor for PPCs in patients undergoing major abdominal surgery.

\section{METHODS}

\section{Study Design and Patients}

Candidates for this prospective observational study were patients undergoing major abdominal surgery from January 2013 to January 2014 at the S. Anna University Hospital of Ferrara. This study was approved by the ethics committee of our institution, and written informed consent was obtained from each subject. The study was registered on Clinicaltrial. gov (registration number: 02229591; principal investigator: Dr. S.S.; registration date: August 28, 2014).

The exclusion criteria were as follows: patients younger than age 18 years, surgical intervention lasting $<2$ hours, and patients' participation refusal.

The severity of chronic dyspnea was rated according to the dyspnea scale proposed by the Medical Research Council. ${ }^{22}$ Anesthesia was induced with propofol (1.5 mg/kg), fentanyl (3 $\mu \mathrm{g} / \mathrm{kg})$, and vecuronium bromide/ rocuronium $(0.1 \mathrm{mg} / \mathrm{kg})$ and maintained with sevoflurane and air-oxygen mixture $50 \% / 50 \%$. Muscle paralysis was monitored by ulnar nerve stimulation. All patients were intubated via a 7.5- or $8.0-\mathrm{mm}$ internal diameter low pressure-cuffed endotracheal tube and ventilated in volumecontrolled mode with the tidal volume and respiratory rate titrated to maintain normocapnia (Table 1). The level of PEEP was set at $5 \mathrm{~cm} \mathrm{H}_{2} \mathrm{O}$ for the duration of surgery. ${ }^{19}$

\section{Procedures}

The determination of EFL during general anesthesia and paralysis was performed using the PEEP test. This test is based on a sudden decrease of expiratory resistance obtained by a subtraction of $3 \mathrm{~cm} \mathrm{H}_{2} \mathrm{O}$ of PEEP during expiration. ${ }^{19} \mathrm{~A}$ patient was considered to have EFL when reducing PEEP by $3 \mathrm{~cm} \mathrm{H}_{2} \mathrm{O}$ did not increase expiratory flow when compared with the previous breath. If expiratory flow increased with PEEP reduction, the patient was considered not flow limited (Fig. 1). We performed the PEEP test at the beginning and at the end of surgery.

\section{Outcomes}

The incidence and type of pulmonary complications within the first 7 postoperative days were recorded by a physician who reviewed the clinical records everyday and was blinded to study group (ie, whether patients were flow limited or not). The details of the definitions of PPCs are reported in the Supplemental Digital Content (Supplemental Appendix 1, http:/ /links.lww.com/AA/B444). ${ }^{23-28}$

\section{Statistical Analysis}

The sample size was calculated according to the primary endpoint: the incidence of PPCs in patients with EFL undergoing major abdominal surgery. We estimated from our previous study ${ }^{19}$ that the prevalence of EFL in elderly patients undergoing general anesthesia for major abdominal surgery was $42 \%$. Assuming that this proportion is significantly different from the null hypothesis value of 0.5 , we calculated that at least 305 patients would be needed to observe differences in the main outcome (type I error rate of 0.05 and a type II error rate of 0.20 [80\% power]). After estimating a $10 \%$ dropout rate (refusal to participate, interruption of intervention, and lost to follow-up), we chose a sample size of 330 patients. Sample size analysis was performed using MedCalc software (MedCalc software 9.3.6.0, Mariakerke, Belgium).

Data are presented as frequencies with percentages and mean \pm standard deviation or medians with 25 th to 75 th percentiles range (interquartile range, 25-75), depending on the type of data and their distribution. The ShapiroWilk test was used to assess the assumption of normality. Categorical data were compared using the $\chi^{2}$ test. Unpaired Student $t$ tests or Mann-Whitney $U$ tests for data with normal or nonnormal distribution, respectively, were used to compare continuous variables.

The association between preoperative baseline patient characteristics and PPCs was modeled using binary logistic regression analysis and is reported as estimated odds ratio and relative 95\% confidence interval (CI). A multivariate logistic regression model was used to estimate the 


\begin{tabular}{|c|c|c|c|}
\hline & Without EFL $(n=229)$ & With EFL ( $n=101)$ & $P$ \\
\hline Age (y) & $65 \pm 15$ & $70 \pm 12$ & .005 \\
\hline Male sex, n (\%) & $120(52)$ & $32(32)$ & .0008 \\
\hline $\mathrm{BMI}\left(\mathrm{kg} / \mathrm{m}^{2}\right)$ & $26 \pm 4$ & $29 \pm 5$ & $<.0001$ \\
\hline ASA, $n(\%)$ & & & .172 \\
\hline I & $14(6)$ & $4(4)$ & .427 \\
\hline II & $95(42)$ & $41(41)$ & .880 \\
\hline III & $115(50)$ & $49(48)$ & .775 \\
\hline IV & $5(2)$ & $7(7)$ & .034 \\
\hline \multicolumn{4}{|l|}{ Preoperative comorbidities } \\
\hline Lung diseases, $\mathrm{n}(\%)$ & $25(11)$ & $33(33)$ & $<.0001$ \\
\hline COPD & 15 & 18 & .002 \\
\hline Emphysema & 7 & 10 & .010 \\
\hline Bronchial asthma & 3 & 5 & .048 \\
\hline Heart diseases, n (\%) & $44(19)$ & $46(45)$ & $<.0001$ \\
\hline Chronic cardiac ischemia & 17 & 20 & .001 \\
\hline Cardiac arrhythmia & 12 & 11 & .063 \\
\hline Valvular diseases & 5 & 3 & .668 \\
\hline Chronic heart failure & 10 & 12 & .012 \\
\hline Smoking history, $\mathrm{n}(\%)$ & $96(42)$ & $42(42)$ & .954 \\
\hline Current smokers, $\mathrm{n}(\%)$ (quit by at least $1 \mathrm{y}$ ) & $69(30)$ & $33(33)$ & .645 \\
\hline Pack-years & $31 \pm 9$ & $33 \pm 10$ & .073 \\
\hline Preoperative $\mathrm{Spo}_{2}$ (room air) & 98 [97-100] & 97 [96-98] & .0002 \\
\hline MRC & $1.7 \pm 0.9$ & $2.4 \pm 1.1$ & $<.0001$ \\
\hline Length of surgery (min) & $190 \pm 76$ & $208 \pm 85$ & .052 \\
\hline Vascular surgery, $\mathrm{n}(\%)$ & $18(8)$ & $10(10)$ & .690 \\
\hline \multicolumn{4}{|l|}{ Major intestinal surgery, $\mathrm{n}(\%)$} \\
\hline Laparotomic & $113(49)$ & $55(55)$ & .461 \\
\hline Laparoscopic & $98(43)$ & $36(35)$ & .272 \\
\hline Tube caliper 8.0, n (\%) & $113(49)$ & $41(40)$ & .177 \\
\hline $\mathrm{V}_{\mathrm{T}}, \mathrm{mL} / \mathrm{kg}$ & $6.9 \pm 1.3$ & $6.7 \pm 0.9$ & .161 \\
\hline $\mathrm{RR}$, breaths/min & $14 \pm 0.9$ & $13 \pm 1$ & .051 \\
\hline Crystalloids (mL/kg/h) & $3.0[2.3-3.5]$ & $6.0[5.0-9.0]$ & $<.0001$ \\
\hline Urinary output (mL) & $200[0-400]$ & $150[0-300]$ & .139 \\
\hline Transfused patients, n (\%) & $27(12)$ & $13(13)$ & .782 \\
\hline PPCs, n (\%) & $29(13)$ & $42(42)$ & $<.0001$ \\
\hline ICU admission, $\mathrm{n}(\%)$ & $11(5)$ & $17(17)$ & .0003 \\
\hline LOS & $7 \pm 4$ & $9 \pm 4$ & .004 \\
\hline
\end{tabular}

Normally distributed data are expressed as mean \pm standard deviation. Not normally distributed data are expressed as median [interquartile range].

Abbreviations: ASA, American Society of Anesthesiologists physical status classification; BMI, body mass index; COPD, chronic obstructive pulmonary disease; MRC, Medical Research Council scale for dyspnea; ICU, intensive care unit; LOS, length of hospital stay; PPCs, postoperative pulmonary complications; $\mathrm{RR}$, respiratory rate; $\mathrm{Spo}_{2}$, peripheral capillary oxygen saturation; $\mathrm{V}_{\mathrm{T}}$, tidal volume.
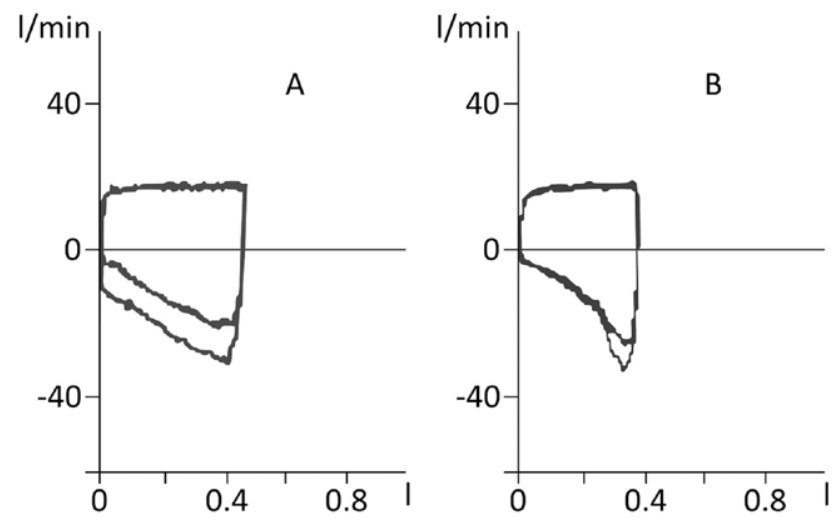

Figure 1. Flow-volume loops of representative patients undergoing positive end-expiratory pressure (PEEP) test. A, Subtraction of $3 \mathrm{~cm} \mathrm{H}_{2} \mathrm{O}$ of PEEP increased the expiratory flow, and the patients were classified as not flow-limited. B, Subtraction of $3 \mathrm{~cm} \mathrm{H}_{2} \mathrm{O}$ of PEEP did not increase expiratory flow, except for a brief initial transient, which is mainly the result of a sudden reduction of volume of the upper airways and heralds flow limitation. See text for further explanations. association between PPCs and EFL adjusting for covariates (age, Medical Research Council [MRC], American Society of Anesthesiologists, and length of surgery). In the same fashion, Poisson regression model with a robust error variance was performed to assess unadjusted and adjusted risk ratios and relative $95 \% \mathrm{CI}$. For multivariate regression, we chose a threshold age $>65$ years based on previous studies of pulmonary complications ${ }^{5}$ and surgical duration $>240$ minutes based on the third quartile for surgical duration for intestinal procedures in our hospital.

Statistical analyses were performed using SPSS 20.0 statistical software (SPSS Inc, Chicago, IL) and STATA (StataCorp. 2011, Stata Statistical Software: Release 12; StataCorp LP, College Station, TX). In all statistical analyses, a 2-tailed test was performed and the $P$ value $\leq .05$ was considered statistically significant.

\section{RESULTS}

Three hundred thirty patients were enrolled. Their clinical characteristics are presented in Table 1 and the flowchart 
of the study in Figure 2. After anesthesia induction, 64 patients (19.3\%) had EFL. All patients with EFL at the beginning of the procedure and an additional 37 (11.3\%) patients demonstrated EFL at the end of surgery. Hence, by applying the PEEP test, 2 groups of patients were identified: the EFL group (101 patients, 31\%) and the no EFL group (229 patients, 69\%) (Fig. 1). Patients who developed EFL during anesthesia were older and had a higher body mass index and an MRC score. No differences were detected in terms of duration and the type of surgery (Table 1).

In univariate analysis, patients with EFL had a higher percentage of PPCs $(P=.003$; Table 1$)$. Acute respiratory failure, respiratory infection, and pneumonia were more common in the group with EFL (Table 2). Among the patients with EFL who developed an acute respiratory failure, 73\% were reintubated and $27 \%$ were managed with noninvasive positive pressure ventilation. The intensive care unit admission rate was higher, and hospital length of stay was longer in patients with EFL (Table 1).

In multivariate analysis (Table 3), factors associated with PPCs included the presence of EFL $(P<.0001)$, MRC dyspnea score $\geq 3(P=.002)$, and age $\geq 65$ years $(P=.023)$. The presence of EFL doubled the possibility of developing PPCs after major abdominal surgery (odds ratio: 4.2; 95\% CI, 2.3-7.6). The odds ratios for MRC $\geq 3$ and age $\geq 65$ years were 2.6 and 2.1 , respectively (Table 3 ).

Using Poisson regression analysis (Table 4), we estimated the relative risk of PPCs given the intraoperative presence of EFL $(P<.0001)$, MRC dyspnea score $\geq 3(P=.006)$, and age $\geq 65$ years $(P=.024)$. The presence of EFL increased the risk of developing PPCs after major abdominal surgery by $>50 \%$ (risk ratio, 2.7; 95\% CI, 1.7-4.2). The relative risk factors for $\mathrm{MRC} \geq 3$ and age $\geq 65$ years were 1.8 and 1.7 , respectively (Table 4).

\section{DISCUSSION}

In this study, we found in patients undergoing major abdominal surgery that EFL, as assessed intraoperatively by the PEEP test, was a significant risk factor for PPC.

Our data are consistent with the existing literature. The presence of EFL has been reported in patients with a wide variety of lung diseases and has recently been demonstrated

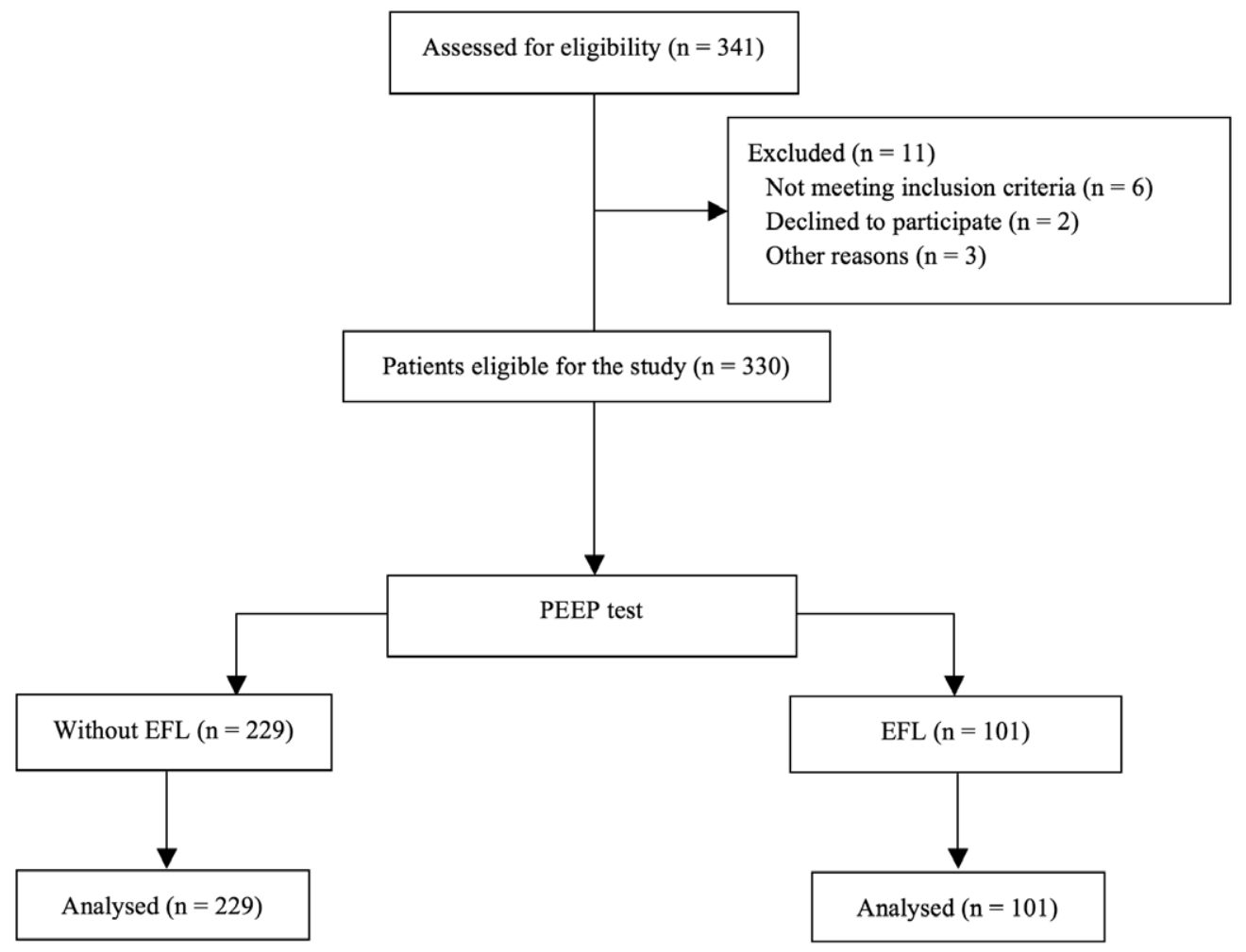

Figure 2. Flowchart of the study.

\begin{tabular}{|c|c|c|c|}
\hline & Without EFL (n = 229) & With EFL $(n=101)$ & $\boldsymbol{P}$ \\
\hline Hypoxemia, n (\%) & $18(8)$ & $14(14)$ & .89 \\
\hline Acute respiratory failure, $\mathrm{n}(\%)$ & $2(1)$ & $11(11)$ & $<.001$ \\
\hline Invasive mechanical ventilation, $\mathrm{n}$ & 2 & 8 & \\
\hline Noninvasive mechanical ventilation, $\mathrm{n}$ & 0 & 3 & \\
\hline Bronchospasm, n (\%) & $2(1)$ & $2(2)$ & .72 \\
\hline Respiratory infection, $\mathrm{n}(\%)$ & 7 (3) & $10(10)$ & .01 \\
\hline Pneumonia, $\mathrm{n}(\%)$ & 0 & $5(5)$ & .001 \\
\hline
\end{tabular}

Abbreviations: EFL, expiratory flow limitation; PPCs, postoperative pulmonary complications. 


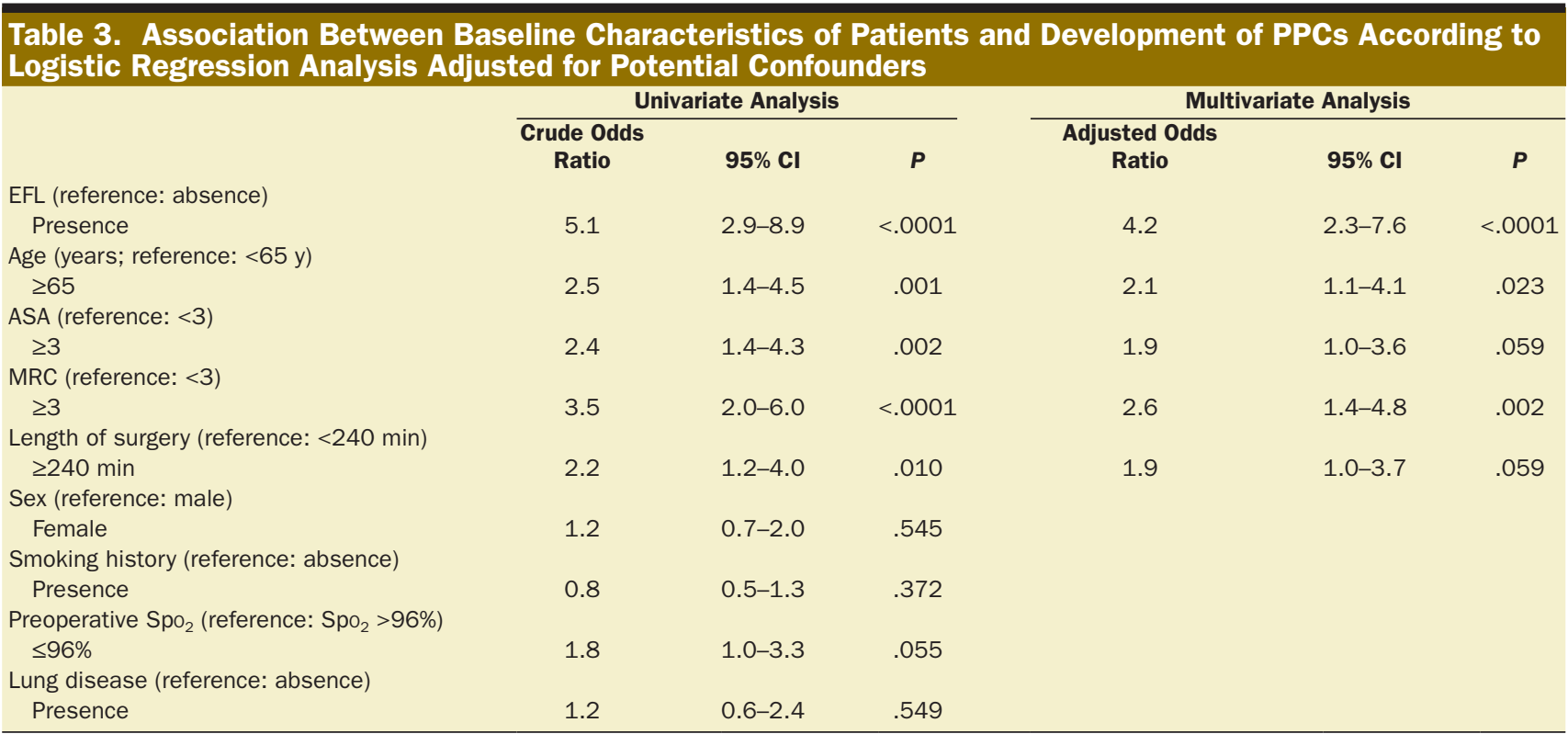

A series of exploratory analyses were performed to assess for potential 2-way interaction between EFL and the other categorical explanatory variables, and no significant 2-way interactions were detected (all $P \geq .27$ ).

Abbreviations: ASA, American Society of Anesthesiologists physical status classification; Cl, confidence interval; EFL, expiratory flow limitation; MRC, Medical Research Council scale for dyspnea; PPCs, postoperative pulmonary complications; $\mathrm{SpO}_{2}$, peripheral capillary oxygen saturation.

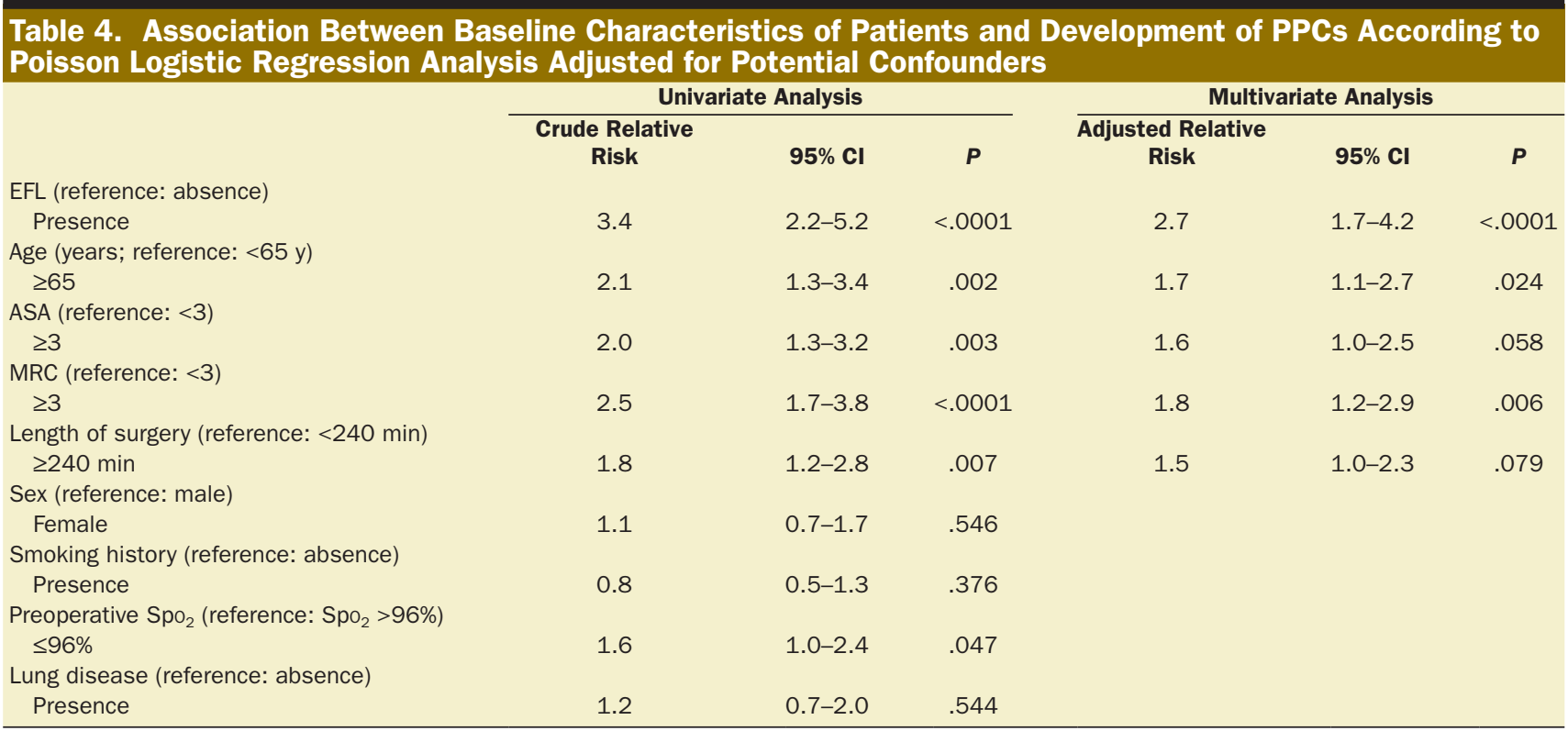

A series of exploratory analyses were performed to assess for potential 2-way interaction between EFL and the other categorical explanatory variables, and no significant 2-way interactions were detected (all $P \geq .19$ ).

Abbreviations: ASA, American Society of Anesthesiologists physical status classification; EFL, expiratory flow limitation; MRC, Medical Research Council scale for dyspnea; PPCs, postoperative pulmonary complications; $\mathrm{Spo}_{2}$, peripheral capillary oxygen saturation.

in patients undergoing general anesthesia. ${ }^{19}$ The supine position (among others) together with pulmonary effects of anesthesia causes a decrease in functional residual capacity. ${ }^{20}$ This decrease promotes either cyclic airway closure at endexpiration or continuous closure during the entire breath. Such intermittent airways closure can cause ventilationperfusion mismatch that impede oxygenation. Moreover, the repetitive closing and opening of airways during tidal ventilation promotes an inflammatory reaction that can predispose to pulmonary infection. ${ }^{29}$ Continuous airway closure may cause atelectasis because of absorption of trapped gas behind the occluded airway, ${ }^{20}$ which can lead to shunt and postobstructive infection. ${ }^{30}$ However, because not all patients undergoing general anesthesia develop EFL, factors related to patients themselves likely act in promoting this phenomenon. The age-related increase of closing capacity is patientspecific and reflects both loss of lung recoil and decreased resistance of the peripheral airways to collapse. ${ }^{31,32}$ Moreover, with advancing age, maximal expiratory flow decreases at low lung volume, making older patients more susceptible 
to tidal EFL. These alterations of respiratory function can be further enhanced in patients with a smoking history. ${ }^{32}$ All in all, when patients become flow-limited during general anesthesia, it is likely that their respiratory function is more compromised compared with patients without EFL.

Several mechanisms may link the presence of EFL to PPCs in patients undergoing major surgery. The marked reduction of expiratory flow, which is independent of expiratory muscle activity, can impair cough and hence secretion removal. ${ }^{16}$ Retention of secretions in the respiratory tract is associated with the development of atelectasis, bronchitis, bronchopneumonia, and peripheral airway obstruction. ${ }^{33}$ Taken together, these mechanisms support the link between PPCs and postoperative infection/pneumonia we observed.

Our findings also have clinical relevance. Because their risk of PPCs is higher, patients who exhibit EFL during surgery should be managed more cautiously. Great effort should be made to prevent postoperative hypoxia, retention of secretions, and respiratory infections (Table 2). Additional pulmonary therapy such as aggressive pulmonary toilet and/or greater monitoring may also have benefit. Further work is needed to determine whether preventive strategies based on the detection of EFL during surgery can improve outcomes.

In the current literature, PPCs have been associated with generic risk factors such as a smoking history, ${ }^{34}$ exacerbation of asthma, chronic heart failure, and COPD. ${ }^{2,5}$ However, these factors have a limited ability to predict which patients are more prone to develop PPCs, ${ }^{5}$ possibly because, as has been previously demonstrated for patients with COPD, the disease is often based on clinical criteria rather than a confirmed spirometric diagnosis. ${ }^{35}$ In addition, preoperative pulmonary function tests do not always identify patients who develop PPCs ${ }^{36}$ nor do they capture severity of airway obstruction in patients with COPD. ${ }^{10}$ Although DLCO has correlated with postoperative mortality in patients undergoing surgical resection for lung cancer, ${ }^{37}$ the DLCO test requires special equipment, is time-consuming for patients, and is costly. In contrast, the PEEP test we used to determine the presence of EFL is very easy to perform both in the operating room and intensive care unit and does not require the use of expensive devices. Moreover, the PEEP test allows detection of EFL for the entire duration of the surgical procedure because patients can become flow-limited at any point during surgery. ${ }^{19}$

The strength of EFL as a risk factor for PPCs is that it does not pertain only to a specific disease state such as COPD, but can be found in patients with different disease processes. Our data support the argument that EFL identifies patients who are overall more ill by finding an increased rate of complications, both respiratory and cardiovascular, and by an increased length of stay of approximately 2 days (7 vs 9 days; Table 1 ).

Our multivariate analysis also identified the MRC dyspnea scale ${ }^{22}$ as a risk factor for PPCs (Table 1). This observation was not surprising because the MRC scale has previously correlated with EFL in patients with COPD. ${ }^{10}$ The determination of MRC scale before surgery may then identify those patients in whom the presence of EFL should be determined.
One previously described risk factor for PPCs was the preoperative $\mathrm{SpO}_{2}$. However, we did not find this parameter significant during logistic regression analysis, even in absence of EFL. This lack of significance may have been because few of our patients experienced $\mathrm{Spo}_{2}$ values $<90 \%$ (Table 1).

Our study has several limitations. Because the PEEP test allows determination of EFL only after anesthesia induction, it cannot be used for preoperative risk stratification. However, our results suggest that an MRC scale $>3$ correlates well with PPCs (Table 3) and may also help to identify those patients who are at greater risk of developing EFL. The PEEP test will give the definitive answer to this clinical question. Of note, in patients with COPD, EFL is the respiratory variable that better correlates with the MRC scale. ${ }^{10}$

Furthermore, we have previously demonstrated that the use of PEEP can partially prevent the development of EFL. ${ }^{19}$ Because the patients enrolled in this study were ventilated with $5 \mathrm{~cm} \mathrm{H}_{2} \mathrm{O}$ of PEEP, our results may not be applicable to patients ventilated at zero-PEEP level, in which the incidence of PPCs may have been even higher.

In conclusion, we found in a prospective observational trial that the intraoperative presence of EFL is a risk factor for PPC in patients undergoing major abdominal surgery. Further work is needed to better understand the relevance of EFL on postoperative pulmonary outcomes.

\section{DISCLOSURES}

Name: Savino Spadaro, MD.

Contribution: This author designed the study. He helped conduct the study, collect the data, analyze the data, and write the manuscript.

Name: Gaetano Caramori, MD.

Contribution: This author helped design the study and reviewed and constructively criticized the manuscript.

Name: Chiara Rizzuto, MD.

Contribution: This author helped enroll the patients and analyze the data.

Name: Francesco Mojoli, MD.

Contribution: This author helped design the study, and reviewed and constructively criticized the manuscript.

Name: Gianluca Zani, MD.

Contribution: This author helped design the study and analyze the data.

Name: Riccardo Ragazzi, MD.

Contribution: This author helped design the study and analyze the data.

Name: Giorgia Valpiani, StatD.

Contribution: This author helped conduct the study and carried out the statistical analysis.

Name: Francesca Dalla Corte, MD.

Contribution: This author helped conduct the study and carried out the statistical analysis.

Name: Elisabetta Marangoni, MD.

Contribution: This author contributed to data analysis.

Name: Carlo Alberto Volta, MD.

Contribution: This author helped design the study, analyze the data, and write the manuscript.

This manuscript was handled by: Avery Tung, MD, FCCM.

\section{REFERENCES}

1. Smetana GW. Preoperative pulmonary evaluation. $N$ Engl J Med. 1999;340:937-944.

2. Smetana GW, Lawrence VA, Cornell JE; American College of Physicians. Preoperative pulmonary risk stratification for 
noncardiothoracic surgery: systematic review for the American College of Physicians. Ann Intern Med. 2006;144:581-595.

3. Qaseem A, Snow V, Fitterman N, et al; Clinical Efficacy Assessment Subcommittee of the American College of Physicians. Risk assessment for and strategies to reduce perioperative pulmonary complications for patients undergoing noncardiothoracic surgery: a guideline from the American College of Physicians. Ann Intern Med. 2006;144:575-580.

4. DeHert S, Imberger G, Carlisle J, et al; Task Force on Preoperative Evaluation of the Adult Noncardiac Surgery Patient of the European Society of Anaesthesiology. Preoperative evaluation of the adult patient undergoing non-cardiac surgery: guidelines from the European Society of Anaesthesiology. Eur J Anaesthesiol. 2011;28:684-722.

5. Canet J, Gallart L, Gomar C, et al; ARISCAT Group. Prediction of postoperative pulmonary complications in a populationbased surgical cohort. Anesthesiology. 2010;113:1338-1350.

6. Hemmes SN, Gama de Abreu M, et al; PROVE Network Investigators for the Clinical Trial Network of the European Society of Anaesthesiology. High versus low positive end-expiratory pressure during general anaesthesia for open abdominal surgery (PROVHILO trial): a multicentre randomized controlled trial. Lancet. 2014;384:495-503.

7. McAlister FA, Khan NA, Straus SE, et al. Accuracy of the preoperative assessment in predicting pulmonary risk after nonthoracic surgery. Am J Respir Crit Care Med. 2003;167:741-744.

8. Pellegrino R, Viegi G, Brusasco V, et al. Interpretative strategies for lung function tests. Eur Respir J. 2005;26:948-968.

9. Volta CA, Ploysongsang Y, Eltayara L, Sulc J, Milic-Emili J. A simple method to monitor performance of forced vital capacity. J Appl Physiol (1985). 1996;80:693-698.

10. Eltayara L, Becklake MR, Volta CA, Milic-Emili J. Relationship between chronic dyspnea and expiratory flow limitation in patients with chronic obstructive pulmonary disease. Am J Respir Crit Care Med. 1996;154:1726-1734.

11. Duguet A, Tantucci C, Lozinguez O, et al. Expiratory flow limitation as a determinant of orthopnea in acute left heart failure. J Am Coll Cardiol. 2000;35:690-700.

12. Torchio R, Gulotta C, Greco-Lucchina P, et al. Orthopnea and tidal expiratory flow limitation in chronic heart failure. Chest. 2006;130:472-479.

13. Goetghebeur D, Sarni D, Grossi Y, et al. Tidal expiratory flow limitation and chronic dyspnoea in patients with cystic fibrosis. Eur Respir J. 2002;19:492-498.

14. Koutsoukou A, Armaganidis A, Stavrakaki-Kallergi C, et al. Expiratory flow limitation and intrinsic positive end-expiratory pressure at zero positive end-expiratory pressure in patients with adult respiratory distress syndrome. Am J Respir Crit Care Med. 2000;161:1590-1596.

15. Polese G, Lubli P, Mazzucco A, Luzzani A, Rossi A. Effects of open heart surgery on respiratory mechanics. Intensive Care Med. 1999;25:1092-1099.

16. Alvisi V, Marangoni E, Zannoli S, et al. Pulmonary function and expiratory flow limitation in acute cervical spinal cord injury. Arch Phys Med Rehabil. 2012;93:1950-1956.

17. Koutsoukou A, Koulouris N, Bekos B, et al. Expiratory flow limitation in morbidly obese postoperative mechanically ventilated patients. Acta Anaesthesiol Scand. 2004;48:1080-1088.

18. Mayer P, Pépin JL, Bettega G, et al. Relationship between body mass index, age and upper airway measurements in snorers and sleep apnoea patients. Eur Respir J. 1996;9:1801-1809.

19. Marangoni E, Alvisi V, Ragazzi R, et al. Respiratory mechanics at different PEEP level during general anesthesia in the elderly: a pilot study. Minerva Anestesiol. 2012;78:1205-1214.
20. Hedenstierna G, Edmark L. Mechanisms of atelectasis in the perioperative period. Best Pract Res Clin Anaesthesiol. 2010;24:157-169.

21. D'Angelo E, Pecchiari M, Baraggia P, Saetta M, Balestro E, Milic-Emili J. Low-volume ventilation causes peripheral airway injury and increased airway resistance in normal rabbits. $J$ Appl Physiol (1985). 2002;92:949-956.

22. Mahler DA, Wells CK. Evaluation of clinical methods for rating dyspnea. Chest. 1988;93:580-586.

23. Russell GB, Graybeal JM. Hypoxemic episodes of patients in a postanesthesia care unit. Chest. 1993;104:899-903

24. Hemmes SN, Severgnini P, Jaber S, et al. Rationale and study design of PROVHILO-a worldwide multicenter randomized controlled trial on protective ventilation during general anesthesia for open abdominal surgery. Trials. 2011;12:111.

25. Jammer I, Wickboldt N, Sander M, et al; European Society of Anaesthesiology (ESA) and the European Society of Intensive Care Medicine (ESICM); European Society of Anaesthesiology; European Society of Intensive Care Medicine. Standards for definitions and use of outcome measures for clinical effectiveness research in perioperative medicine: European Perioperative Clinical Outcome (EPCO) definitions: a statement from the ESA-ESICM joint taskforce on perioperative outcome measures. Eur J Anaesthesiol. 2015;32:88-105.

26. Arozullah AM, Khuri SF, Henderson WG, Daley J; Participants in the National Veterans Affairs Surgical Quality Improvement Program. Development and validation of a multifactorial risk index for predicting postoperative pneumonia after major noncardiac surgery. Ann Intern Med. 2001;135:847-857.

27. Mitchell CK, Smoger SH, Pfeifer MP, et al. Multivariate analysis of factors associated with postoperative pulmonary complications following general elective surgery. Arch Surg. 1998;133:194-198.

28. Horan TC, Andrus M, Dudeck MA. CDC/NHSN surveillance definition of health care-associated infection and criteria for specific types of infections in the acute care setting. Am J Infect Control. 2008;36:309-332.

29. van Kaam AH, Lachmann RA, Herting E, et al. Reducing atelectasis attenuates bacterial growth and translocation in experimental pneumonia. Am J Respir Crit Care Med. 2004;169:1046-1053.

30. Holland J, Milic-Emili J, Macklem PT, Bates DV. Regional distribution of pulmonary ventilation and perfusion in elderly subjects. J Clin Invest. 1968;47:81-92.

31. Turner JM, Mead J, Wohl ME. Elasticity of human lungs in relation to age. J Appl Physiol. 1968;25:664-671.

32. Taveira Da Silva AM, Hamosh P. Effect of smoking a cigarette on the density dependence of maximal expiratory flow. Respiration. 1982;43:258-262.

33. Kiwerski JE. Factors contributing to the increased threat to life following spinal cord injury. Paraplegia. 1993;31:793-799.

34. Jeong BH, Shin B, Eom JS, et al. Development of a prediction rule for estimating postoperative pulmonary complications. PLoS One. 2014;9:e113656.

35. Sutherland ER, Cherniack RM. Management of chronic obstructive pulmonary disease. N Engl J Med. 2004;350:2689-2697.

36. McAlister FA, Bertsch K, Man J, Bradley J, Jacka M. Incidence of and risk factors for pulmonary complications after nonthoracic surgery. Am J Respir Crit Care Med. 2005;171:514-517.

37. Wang J, Olak J, Ferguson MK. Diffusing capacity predicts operative mortality but not long-term survival after resection for lung cancer. J Thorac Cardiovasc Surg. 1999;117:581-586. 